
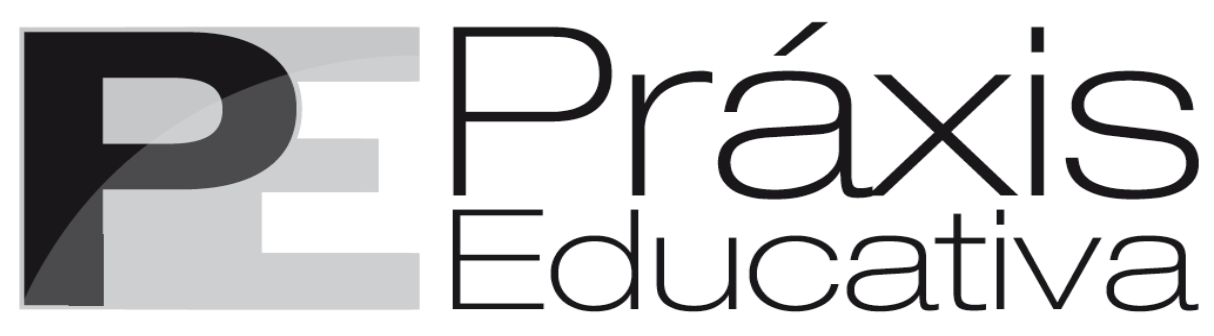

ISSN 1809-4031

eISSN 1809-4309

https://doi.org/10.5212/PraxEduc.v.16.16539.023

\title{
Paulo Freire e os estudos culturais: pistas para convergências possíveis ${ }^{*}$
}

\section{Paulo Freire and cultural studies: clues for possible convergences}

\section{Paulo Freire y los estudios culturales: pistas para convergencias posibles}

José Licínio Backes**

iD https:/ / orcid.org/0000-0001-9013-8537

Ruth Pavan ${ }^{* * *}$

(D) https://orcid.org/0000-0001-8979-1125

Andréa Rosana Fetzner ${ }^{* * *}$

(iD) https:// orcid.org/0000-0002-0034-4095

Resumo: O objetivo deste artigo foi analisar possíveis convergências entre o pensamento de Paulo Freire e os estudos culturais. Para tanto, investigaram-se as obras de Freire e Hall, considerando-se sua concepção de história, a presença de Marx, a centralidade da cultura, a importância da linguagem e o impacto dos estudos feministas e de raça. Argumenta-se que ambos construíram campos teóricos avessos a reducionismos e propuseram a articulação entre classe, raça e gênero como forma de tornar a teoria/política um meio de fazer a diferença, na perspectiva de lutar contra todas as formas de opressão. Conclui-se que há convergências possíveis entre Paulo Freire e os estudos culturais e que elas podem ser uma alternativa promissora para a construção dos inéditos viáveis, que Freire sempre defendeu.

Palavras-chave: Paulo Freire. Stuart Hall. Estudos culturais.

Abstract: The aim of this paper was to analyze possible convergences between Paulo Freire's thinking and Cultural Studies. In order to do that, Freire and Hall's works were investigated, considering their conception of history, the presence of Marx, the centrality of culture, the importance of language, and the impact of feminist and race studies. It has been argued that both built theoretical fields averse to reductionisms and

\footnotetext{
* Financiamento: Conselho Nacional de Desenvolvimento Científico e Tecnológico (CNPq).

** Doutor em Educação. Professor do Programa de Pós-Graduação em Educação - Mestrado e Doutorado da Universidade Católica Dom Bosco. Bolsista Produtividade CNPq - 1D. E-mail: <backes@ucdb.br>.

*** Doutora em Educação. Professora do Programa de Pós-Graduação em Educação - Mestrado e Doutorado da Universidade Católica Dom Bosco. Bolsista Produtividade CNPq - 2. E-mail: <ruth@ucdb.br>.

**** Doutora em Educação. Professora Associada ao Programa de Pós-Graduação em Educação - Mestrado e Doutorado da Universidade Federal do Estado do Rio de Janeiro (UNIRIO) e do Programa de Pós-Graduação em Música - Mestrado e Doutorado da Universidade Federal do Estado do Rio de Janeiro (UNIRIO). E-mail: $<$ andrea.fetzner@unirio.br>.
} 
proposed an articulation between class, race and gender as a way to turn theory/policy into a means to make a difference, from the perspective of struggling against all kinds of oppression. The conclusion is that there are possible convergences between Paulo Freire and the Cultural Studies, and they may be a promising alternative for the construction of the viable unprecedented, which he always defended.

Keywords: Paulo Freire. Stuart Hall. Cultural Studies.

Resumen: El objetivo de este artículo fue analizar posibles convergencias entre el pensamiento de Paulo Freire y los estudios culturales. Para esto, se analizaron las obras de Freire y Hall, considerando su concepción de historia, la presencia de Marx, la centralidad de la cultura, la importancia del lenguaje y el impacto de los estudios feministas y de raza. Se argumenta que ambos construyeron campos teóricos contrarios a reduccionismos y propusieron la articulación entre clase, raza y género como forma de hacer de la teoría/política un medio de marcar la diferencia, en la perspectiva de luchar contra todas las formas de opresión. Se concluye que hay convergencias posibles entre Paulo Freire y los estudios culturales y que ellas pueden ser una alternativa prometedora para la construcción de los inéditos viables, que Freire siempre defendió.

Palabras clave: Paulo Freire. Stuart Hall. Estudios culturales.

\section{Introdução}

Neste artigo, argumentamos que é possível encontrar convergências entre os estudos culturais e Paulo Freire. No processo de argumentação relacionado aos estudos culturais, recorremos a Stuart Hall, autor de destaque internacional que teve grande importância no processo de constituição dos estudos culturais no Centro de Birmingham e que, no Brasil, foi fundamental para a emergência e a consolidação do campo.

Entendemos que há pistas suficientes para mostrar que, embora haja muitos pontos de divergência entre Paulo Freire e os estudos culturais, há também vários pontos possíveis de convergência, aos quais daremos ênfase, mas sem supor que possa haver um encaixe perfeito entre ambos. No processo de argumentação, tomamos o próprio surgimento e a constituição do campo dos estudos culturais, descritos por Hall (2003), para destacar que há convergências entre a gestação e as transformações dos estudos culturais e do pensamento de Paulo Freire.

No primeiro momento do artigo, desenvolvemos a contextualização dos estudos culturais, situamos a temática e ressaltamos o reconhecimento internacional de Stuart Hall e Paulo Freire. Em seguida, apresentamos os principais movimentos ou, utilizando a expressão de Hall (2003), as principais viradas que impactaram os estudos culturais (crítica à história mecanicista e ao marxismo determinista, indicação da centralidade da cultura e da importância da linguagem, destaque à relevância dos estudos feministas e de raça), apontando possíveis convergências com Paulo Freire. Concluímos com a necessidade de continuarmos aprendendo, com os dois autores, a lutar pela transformação da realidade.

\section{Contextualizando a temática}

Os estudos culturais geralmente têm a sua emergência "[...] associada ao Centro de Birmingham, Reino Unido, nos anos 1960, bem como às tendências que têm (re)configurado tais estudos no encontro com outras tradições ao longo do tempo" (WORTMANN; SANTOS; RIPOLL, 2019, p. 2). Embora Stuart Hall não esteja incluído no trio fundador dos estudos culturais (formado por Richard Hoggart, Raymond Williams e Edward Palmer Thompson), sua importância é mundialmente reconhecida. Stuart Hall, “[...] ao substituir Hoggart na direção do Centro, de 1969 a 1979, incentivou o desenvolvimento de estudos etnográficos, análises dos meios massivos e a investigação de práticas de resistência dentro de subculturas” (ESCOSTEGUY, 1998, p. 89). 
O reconhecimento mundial da obra de Stuart Hall justifica a escolha do autor para indicar pistas de aproximação entre os estudos culturais e Paulo Freire. Além disso, os estudos de Hall (2003) foram decisivos para a entrada dos estudos culturais no Brasil, por volta da metade da década de 1990. Como destacam Costa, Wortmann e Silveira (2014, p. 641), “[...] as contribuições de Stuart Hall despontam como marco no advento de novas possibilidades de interpretação e entendimento de questões da área". Ainda segundo as autoras, sua chegada representou um momento de ebulição intelectual, em função de novas possibilidades teóricas, metodológicas e de análise.

Stuart Hall viveu uma tensão permanente entre a política e o trabalho intelectual, defendendo a sua indissociabilidade. Segundo Sovik (2014, p. 79), “[...] conversar com ele [Stuart Hall] era entrar em um mundo em que fazer reflexões que tivessem alguma repercussão política era o objeto, o problema, o jogo a ser jogado". A relação não era no sentido de aliar-se ao poder, mas de contestá-lo, pois ele "[...] argumentava que os intelectuais tradicionais alinham-se com o poder enquanto os críticos interrogam-no, testam-no, expõem suas consequências" (COSTA; WORTMANN; SILVEIRA, 2014, p. 638). Via o trabalho intelectual como uma forma de fazer diferença e modificar os interesses e as forças políticas. Para ele, segundo Costa, Wortmann e Silveira (2014, p. 640), "[...] a teoria precisa dar conta da complexidade das conjunturas para gerar intervenções políticas".

Uma questão que chama atenção e que, de certa forma, também explica a produção deste artigo é que as mesmas autoras, em outro texto, associam o surgimento dos estudos culturais, entre outros fatores, ao momento "[...] que alguns de seus docentes ansiavam promover a desarticulação do campo educativo das conexões que o atrelavam fortemente ao pensamento freiriano" (WORTMANN; COSTA; SILVEIRA, 2015, p. 33). Contudo, este artigo traz algumas reflexões que podem contribuir na articulação entre os dois campos, às vezes, vistos como divergentes.

Não deixa de ser, no mínimo, curioso que os estudos culturais no Brasil tenham se originado, conforme apontam as autoras, em parte, em função do desejo de desarticular a educação do pensamento freiriano, porque, como pretendemos argumentar, há convergências possíveis. No entanto, apesar de curioso, foge ao objetivo deste artigo tratar disso. Não nos deteremos no que Freire incomodava, e talvez, em maior parte, no que os freirianos incomodavam, nem nos interesses que estavam implicados, nem nos saberes/poderes que os mobilizaram, nem nos efeitos que a ânsia pela desarticulação do pensamento freiriano trouxe para os estudos culturais. Nossa questão central é argumentar que, apesar dessa marca de origem no Brasil, assumida por parte de seus praticantes, os estudos culturais, um campo teórico que se assume ora como antidisciplinar, ora como pós-disciplinar, ora como interdisciplinar, ora como multidisciplinar, ora com algumas dessas ou todas essas características, podem articular-se com as teorizações de Paulo Freire.

Assim como Stuart Hall, Paulo Freire tem muita importância no Brasil e é reconhecido internacionalmente. Se, nos últimos anos, ele tem sido alvo da onda conservadora que marca a política brasileira, também é verdade que houve, por parte do campo da educação, um redizer e reviver da sua pedagogia. Recorremos ao próprio Freire (1999, p. 17) para explicar que "[...] falar do dito não é apenas re-dizer o dito mas reviver o vivido que gerou o dizer que agora, no tempo do redizer, de novo se diz. Redizer, falar do dito, por isso envolve ouvir novamente o dito pelo outro sobre ou por causa do nosso dizer" (FREIRE, 1999, p. 17). Esse reviver e redizer pode ser percebido nos vários dossiês já publicados ou com chamada aberta sobre Paulo Freire: Revista eCurriculum (Pontifícia Universidade Católica de São Paulo - PUC-SP), Revista Práxis Educativa (Universidade Estadual de Ponta Grossa - UEPG), Revista ECCOS (Universidade Nove de Julho UNINOVE), Revista Pro-Posições (Universidade Estadual de Campinas - UNICAMP), Educação em Revista (Universidade Federal de Minas Gerais - UFMG), Linhas Críticas (Universidade de Brasília UnB), Reflexão e Ação (Universidade de Santa Cruz do Sul - UNISC), Revista Anthesis (Universidade 
Federal do Acre - UFAC), Revista REPECULT (Universidade Federal Rural do Rio de Janeiro UFRRJ), Revista Espaço Pedagógico (Universidade de Passo Fundo - UPF), Educar em Revista (Universidade Federal do Paraná - UFPR), entre outros.

Para Freire (2002), o trabalho teórico e intelectual precisa estar associado ao compromisso político de transformar a realidade injusta e opressora da sociedade capitalista. É na articulação permanente entre teoria e ação, e não na sua dissociação, que está a chave da transformação. Para o autor, "[...] a reflexão crítica sobre a prática se torna uma exigência da relação Teoria/Prática sem a qual a teoria pode ir virando blablablá e a prática, ativismo" (FREIRE, 2002, p. 24).

Como já evidenciado, Paulo Freire é reconhecido internacionalmente. Segundo Lima (2018), é um autor clássico e um dos maiores pedagogos do século XX:

Trata-se de um autor que considero um clássico do pensamento educacional crítico. A obra de Freire é seminal à Pedagogia Crítica. Como autor clássico, creio que terá condições para resistir à erosão do tempo, porque aborda tópicos centrais e porque a sua obra mantém a capacidade de dialogar com os leitores de cada tempo histórico sobre os problemas de sua condição humana e da sua educação. Por isso Freire continua atual para além de se destacar como um dos maiores pedagogos do século passado. (LIMA, 2018, p. 29).

Autores estadunidenses do campo da pedagogia crítica que dão ênfase à cultura em suas análises, como Giroux (1997), McLaren (1997) e Apple (2006), citados recorrentemente por teóricos brasileiros dos estudos culturais, também sublinham a importância de Paulo Freire. Apple (2006, p. 13) salienta que foi com militantes brasileiros e especialmente com Freire que aprendeu o que é uma pedagogia digna. Segundo o autor, "[...] por meio da intensa interação que tive com Paulo Freire [...] e com eles aprendi - a construir uma educação digna no Brasil". McLaren (1997, p. 327), referindo-se a Paulo Freire, diz haver poucos educadores que "[...] caminham tão sabiamente e com tanta determinação entre as fronteiras da linguagem e da cultura". Em entrevista publicada na Revista Práxis Educativa, concedida a Paula e Portela (2021, p. 9), McLaren afirmou em relação a Freire: "Ele virou minha vida como professor de cabeça para baixo. Ele me ajudou a entender meu próprio privilégio racial em uma sociedade multirracial e multicultura". Giroux (1997, p. 156) vê em Freire um teórico radicalmente a favor da vida e contra todos os processos de opressão, sempre preocupado com um modo de tornarmo-nos melhores como humanos. Para o autor, "[...] a obra e presença de Freire estão aí não apenas para nos lembrar o que somos, mas também para sugerir no que podemos nos transformar".

Acreditamos que, em um momento histórico brasileiro em que Paulo Freire tem sido atacado pelo campo conservador, propor pistas e possibilidades de articulá-lo com os estudos culturais pode ter uma relevância ímpar. Tal articulação pode ser fundamental para que os estudos culturais não se distanciem de sua origem histórica, do Centro de Birmingham, no sentido de colocar em xeque a concepção arnoldiana de cultura, segundo a qual há grupos que possuem cultura ou pertencem à alta cultura e outros que não possuem cultura ou pertencem à baixa cultura.

Ressaltamos que Hall (2003) sempre esteve preocupado com a institucionalização dos estudos culturais, que, no seu entender, poderiam levar a um academismo bem-sucedido, mas com pouca relevância política e social, perdendo seu caráter transgressor e contestador, ou, recorrendo à expressão que Hooks ${ }^{1}$ (2015) utiliza para referir-se ao feminismo estadunidense, transformar os estudos culturais em um projeto burguês. Hooks (2015) mostra como o feminismo nos Estados Unidos, ao não levar em conta a dimensão racial e de classe, acabou sendo uma luta em defesa dos

${ }^{1}$ Embora a autora grafe seu nome com letra inicial minúscula, optamos por seguir as normas da Associação Brasileira de Normas Técnicas (ABNT). 
interesses das mulheres da classe média/alta branca. Segundo a autora, “[...] não é por acaso que a luta feminista foi cooptada tão facilmente para servir aos interesses das feministas liberais e conservadoras, já que o feminismo nos Estados Unidos tem sido, até agora, uma ideologia burguesa" (HOOKS, 2015, p. 201). Embora haja problemas específicos das mulheres brancas que também devem ser abordados, esses são incomparáveis às preocupações da maioria das mulheres, que lutam para sobreviver economicamente e contra o racismo e a discriminação. Para ela, "[...] a luta de classes está indissoluvelmente ligada à luta para acabar com o racismo" (HOOKS, 2015, p. 196) e, obviamente, com o sexismo.

Entendemos que, se colocarmos as preocupações de Freire como centrais nos estudos culturais - centrais, como explica Hall (1997), não no sentido de estarem no centro, ao redor do qual tudo se move, mas de atravessarem todas as nossas reflexões -, não corremos o risco de desenvolvermos estudos culturais burgueses, para usar a expressão empregada por Hooks (2015) para referir-se a um tipo de feminismo - o feminismo burguês. Parafraseando Hooks (2015), podemos dizer que, mesmo que os estudantes burgueses da classe média/alta sofram os efeitos de uma sociedade marcada pela lógica neoliberal, esse sofrimento é incomparável ao de milhões de pobres, mulheres, negros, indígenas, sistematicamente vítimas dos processos de opressão, em função de questões de classe, raça, gênero. Por isso, argumentamos que a postura radical "[...] contra a ordem capitalista vigente que inventou esta aberração: a miséria na fartura" (FREIRE, 2002, p. 115) continua fundamental para os praticantes dos estudos culturais.

Como diz Bauman (2001), na sociedade atual, todos são produzidos para fazer escolhas e ser vistos como responsáveis pela construção de suas trajetórias de vida, o que gera angústia e malestar. A angústia de quem tem um excesso de opções disponíveis, caso de uma pequena elite mundial, é muito diferente daquela de quem precisa escolher alimentar-se apenas de manhã ou somente à noite, ou entre ter um salário miserável e ficar sem trabalho. A escolha de quem está em dúvida sobre qual roupa de marca utilizar para identificar-se é muito diferente da escolha entre silenciar diante do racismo sofrido e perder o emprego por ser acusado de criador de problema. A escolha da mulher burguesa branca de como posicionar-se contra o machismo é muito diferente daquela da babá negra, que escolhe cuidar do filho da mulher branca e ser mal paga ou cuidar do próprio filho, mas com menos recursos ainda.

Como Bauman (2001) aponta, se as lutas identitárias não forem também lutas pela redistribuição, elas não vão contribuir para diminuir a desigualdade. Novamente com Freire (2002, p. 114), aprendemos a falar “[...] de resistência, da indignação, da 'justa ira' dos traídos e dos enganados. Do seu direito e do seu dever de rebelar-se contra as transgressões éticas de que são vítimas cada vez mais sofridas".

O caminho que escolhemos mostra que sempre foi possível articular as discussões de Stuart Hall com as de Paulo Freire. No entanto, em função de algumas especificidades históricas, que não são o foco de nosso artigo, essa aproximação não foi desejada quando da entrada dos estudos culturais no Brasil. Acreditamos que, em si, esse caminho que escolhemos já sinaliza tal proximidade. Seguiremos os movimentos e "viradas" pelos quais os estudos culturais passaram, mostrando que esses movimentos estão também presentes nas obras de Paulo Freire. São eles: a importância de considerar a dimensão histórica, mas não de modo mecanicista; o reconhecimento de Marx, mas de forma crítica; a centralidade da cultura; a incorporação dos estudos feministas; e, por fim, a incorporação dos estudos de raça. Embora eles sigam mais ou menos o movimento descrito por Hall (2003), como o próprio autor afirma, isso não significa uma sequência causal e necessária, mas apenas uma forma de contar os movimentos e como eles se articularam, produzindo um conjunto de convergências possíveis. 


\section{Importância de considerar a dimensão histórica}

Podemos também identificar a proximidade entre o que os autores pensam sobre a importância da dimensão histórica e da concepção histórica. Trata-se de reconhecer a radicalidade da história não só do próprio ser humano, mas de tudo que existe. Não existe nada fora da história, mas não se trata de uma concepção histórica factual, mecanicista ou determinista. Entretanto, Hall (2003), ao criticar o determinismo e o mecanicismo histórico, esclarece que isso não quer dizer que não há determinações, mas, sim, que elas não seguem leis prévias. Não há correspondências necessárias, o que não quer dizer que não existam correspondências. Para ele, segundo algumas vertentes teóricas, “[...] no recuo da 'correspondência necessária', tem ocorrido o usual implacável deslize filosófico para o lado oposto; [...] a declaração de que 'não há necessariamente qualquer correspondência" (HALL, 2003, p. 165). Conforme o autor, há "[...] tendências - linhas de força, aberturas ou fechamentos que constrangem, modelam, canalizam e, nesse sentido, 'determinam"” (HALL, 2003, p. 165), mas não são fixas. Não há garantias de que ocorrerão da mesma forma em diferentes contextos, pois "[...] os processos históricos nem sempre surgem no mesmo lugar, nem causam os mesmos efeitos históricos" (HALL, 2003, p. 161).

Ainda que sejam efeitos dos contextos históricos, os seres humanos não são por eles determinados. Isso não significa ausência de determinações históricas, mas, sim, que nem os seres humanos nem as sociedades seguem leis historicamente preestabelecidas. Não há características que estão "[...] irrevogável ou indelevelmente inscritas nas pessoas, o senso político que elas devem ter não se encontra como que inscrito em seus genes sociológicos" (HALL, 2003, p. 168, grifo do autor). Portanto, não há leis inevitáveis a serem seguidas, mas é possível encontrar elos entre a história e os seres humanos que podem (mas não necessariamente) nos levar a um determinado modo de estar e relacionar-se com os outros e com o mundo e a uma determinada formação social e cultural.

Ao analisarmos o pensamento de Freire em relação à história, vemos como há convergência entre a forma de entendê-la, pois o autor também critica o determinismo histórico. Segundo o autor, ao recusar " [...] qualquer interpretação mecanicista da História, recuso igualmente a idealista. A primeira reduz a consciência à pura cópia das estruturas materiais da sociedade; a segunda submete tudo ao todo-poderosismo da consciência" (FREIRE, 1997, p. 26, grifos do autor).

Como forma de sair da lógica determinista, Freire (1999) vê a história como possibilidade. Ao argumentar que uma instituição, como a escola, por exemplo, pode propiciar o desenvolvimento tanto do conhecimento crítico dos estudantes, quanto do conhecimento que favorece a submissão, lembra que nem a história, nem as relações, são mecanicistas. De acordo com Freire (2004, p. 38), "[...] é que na verdade os mecanismos, melhor, as relações que se dão na sociedade, infra e superestruturais são históricas. São contraditórias e não mecanicistas".

Conforme já apontado, as concepções de história de Hall e Freire podem ser aproximadas, pois Freire vê a história como possibilidade, e não como algo inexorável, o que lembra a ideia de não correspondência necessária de Hall. Segundo Freire (1999), uma determinada realidade não possui uma história imutável; a história está sempre no campo das possibilidades, portanto, a "tradição histórica" pode ser "[...] rompida instaurando-se um novo processo" (FREIRE, 1999, p. 28). O autor critica a perspectiva sectária e fatalista, que "[...] nega a história como possibilidade" (FREIRE, 1999, p. 51), pois ela produz apatia diante do mundo, seja pela crença de que a mudança virá porque supostamente as forças determinantes a produzirão, seja acreditando que nada há para ser feito, já que a história segue seu curso natural, determinado. A “[...] História é tempo de possibilidade e não de determinações. E se é tempo de possibilidades, a primeira consequência que vem à tona é a de que a História não apenas é mas também demanda liberdade" (FREIRE, 2001, p. 19).

Práxis Educativa, Ponta Grossa, v. 16, e2116539, p. 1-16, 2021

Disponível em: < https://www.revistas2.uepg.br/index.php/praxiseducativa> 


\section{Reconhecimento da importância de Marx}

Tanto Hall quanto Freire têm suas trajetórias ligadas ao marxismo. Hall (2003), ao contar a genealogia dos estudos culturais, mostra como os autores marxistas, principalmente os que atribuíam uma maior importância à questão cultural, foram importantes na emergência e na constituição do campo dos estudos culturais. No entanto, essa emergência deu-se em um momento de desintegração de certo tipo de marxismo, provocada pelo marxismo stalinista. Contudo, isso não significou a retirada de todas as questões que o marxismo colocava enquanto projeto político. Questões de poder, classe social, exploração, questões econômicas, questões de conhecimento crítico e a questão política da teoria continuam a ocupar a agenda dentro do campo dos estudos culturais.

Para Hall (2003), muitos marxistas confundem o conhecimento com simples reconhecimento. Em função disso, não fazem uma leitura crítica de Marx e, consequentemente, não ampliam o conhecimento que ele produziu, tampouco percebem suas insuficiências, as questões não compreendidas - sejam elas teóricas ou políticas -, nem os silêncios presentes em sua obra. Todos os autores, por mais geniais que sejam, bem como suas obras, têm essas características, e é justamente ao reconhecê-las como incompletas que se pode aprender a pensar e compreender melhor a realidade e os sujeitos.

Hall (2003) aponta que os estudos culturais começaram privilegiando temáticas sobre as quais Marx não se debruçou, mas sem jamais deixar de reconhecer a importância de sua obra. Começaram a privilegiar a cultura, a linguagem, o simbólico, sem ter a pretensão de que, em algum momento, terminasse a tensão entre o marxismo e os estudos culturais. Para Hall (2003, p. 203), "[...] tais questões cruciais referem-se ao que significava trabalhar na vizinhança do marxismo, sobre o marxismo, contra o marxismo, com ele e para tentar desenvolvê-lo".

O autor lembra, ainda, que particularmente uma crítica que não pode deixar de ser feita a Marx é o seu eurocentrismo. Segundo Hall (2003, p. 204), “[...] não responsabilizo Marx por ter nascido onde nasceu; apenas questiono a teoria destinada a apoiar o modelo em torno do qual se encontra articulada: o seu Eurocentrismo". A leitura de que a Europa se encontrava em um estágio mais avançado do desenvolvimento capitalista em razão das suas próprias transformações e de que, por isso, as condições históricas eram mais propícias para a revolução socialista, conforme proposto por Marx, segundo Hall (2003), torna-se muito problemática, não só do ponto de vista político e social, mas também teórico, quando se pensa nos inúmeros países onde o capitalismo foi imposto pela colonização.

Por um lado, a crítica a Marx não fez com que Hall (2003) deixasse de reconhecer sua importância no campo do conhecimento, sendo possíveis as análises dos processos de reprodução das desigualdades e das opressões, sobretudo por meio da categoria de classe. Por outro lado, o autor foi percebendo a insuficiência (não a inutilidade) da categoria de classe para explicar as realidades da segunda metade do século XX e início do século XXI. Ele destaca que a não aceitação do inter-relacionamento classe e raça "[...] provou ser um dos problemas teóricos mais difíceis e complexos de se abordar e que frequentemente tem conduzido à adoção de posições extremas" (HALL, 2003, p. 327). Para o autor, apesar de geralmente a discussão entre raça e classe produzir ávidos defensores em cada lado, a rigor, elas se articulam, fazem parte do mesmo processo, que culmina em uma maior desigualdade. Assim, a questão não é pensar se mais importante é a categoria de raça ou se é a categoria de classe, mas pensar como elas se articulam em contextos específicos.

Um movimento teórico semelhante encontramos em Freire quando aponta que "[...] não há, realidade histórica - mais outra obviedade - que não seja humana. Não há, história sem homens 
como não há, uma história para os homens, mas uma história de homens que, feita por eles, também os faz, como disse Marx" (FREIRE, 2011, p. 175).

Segundo Freire (2011), Marx, com o conceito de práxis, superou a dicotomia entre objetividade e subjetividade:

Em Marx, como em nenhum pensador crítico, realista, jamais se encontrará esta dicotomia. O que Marx criticou e, cientificamente destruiu, não foi a subjetividade, mas o subjetivismo, o psicologismo. A realidade social, objetiva, que não existe por acaso, mas como produto da ação dos homens, também não se transforma por acaso. Se os homens são os produtores desta realidade e se esta, na "invasão da práxis", se volta sobre eles e os condiciona, transformar a realidade opressora é tarefa histórica, é tarefa dos homens. (FREIRE, 2011, p. 51).

Freire (2011), sem se esquecer de Marx, foi construindo seu percurso teórico, sem receio de criticar algumas versões de marxismo, sobretudo, o determinista. Novamente, vemos uma possível aproximação de Hall (2003), pois Freire também critica muitos que se diziam marxistas, em especial quando estes acreditavam que o movimento da história levaria automaticamente ao processo de superação do capitalismo. Para Freire (1999, p. 51), “[...] na verdade, o clima preponderante entre as esquerdas era o do sectarismo que, ao mesmo tempo em que nega a história como possibilidade, gera e proclama uma espécie de 'fatalismo libertador'. O socialismo chega necessariamente...[...]". Assim como Hall (2003), Freire (2001, p. 19) associa essa compreensão a uma incompreensão do marxismo ao afirmar que "[...] uma outra concepção da História [...] é a que reduz o amanhã a um dado. O futuro é um pré-dado, uma espécie de sina, de fado. [...]. A dialética que essa visão da História reclama, e que tem sua origem num certo dogmatismo marxista, é uma dialética domesticada".

Como se vê, apesar de ter uma postura radical em favor dos oprimidos e de reconhecer a importância dos movimentos políticos de esquerda e do marxismo, Freire não deixou de fazer crítica às teorias e aos intelectuais que desejam transformar a realidade baseados em concepções mecanicistas. Segundo o autor, eles não percebem “[...] esta obviedade, a de que a situação concreta em que estão os homens condiciona a sua consciência do mundo e esta as suas atitudes e o seu enfrentamento, pensam que a transformação da realidade se pode fazer em termos mecânicos" (FREIRE, 2011, p. 175).

Como Hall (2003), Freire nunca abandonou a questão de classe em suas análises. De certo modo, pode-se dizer que a classe se manteve como a categoria mais importante ao longo de sua trajetória. O autor, porém, foi percebendo, como podemos observar em suas últimas obras, especialmente na década de 1990, também a importância das lutas feministas e das lutas contra o racismo.

\section{A cultura como categoria central de análise}

Conforme já destacado, Hall (2003), junto a outros autores dos estudos culturais, foi travando uma luta teórica para retirar o caráter elitista de cultura e considerá-la não como um epifenômeno, mas como uma categoria central de análise, portanto como uma categoria epistemológica sem a qual a análise da realidade fica muito fragilizada. Com o questionamento do caráter elitista da cultura, ela "[...] não consiste mais na soma de o 'melhor que foi pensado e dito', considerado como os ápices de uma civilização plenamente realizada - aquele ideal de perfeição ao qual, num sentido antigo, todos aspiravam" (HALL, 2003, p. 135). Essa desconstrução do conceito de cultura foi crucial para reconhecer o seu caráter epistemológico, isto é, para reconhecer o "[...] peso explicativo que o conceito de cultura carrega, e no seu papel constitutivo ao invés de 
dependente, na análise social” (HALL, 1997, p. 32), ou, ainda, “[...] em como a 'cultura' é usada para transformar nossa compreensão, explicação e modelos teóricos do mundo" (HALL, 1997, p. 16).

Sem pretendermos dar conta de todas as transformações epistemológicas produzidas, salientamos as duas que consideramos mais importantes. A primeira refere-se ao fato de conceber a cultura como processo de construção dos sentidos pelos quais os seres humanos interpretam as suas ações e as dos outros, em um terreno marcado por relações de poder que, geralmente, embora não sejam fixas, são desiguais e assimétricas. Com isso, há uma transformação radical: já que todos os seres humanos são capazes de dar sentido às coisas e interpretar as suas ações e as dos outros, reconhece-se que todos os seres humanos são produtores de cultura e que a distinção entre quem "tem" e não tem cultura se torna sem sentido. O que vai fazer com que um sentido seja reconhecido como válido ou mais válido são as relações de poder e não o suposto pertencimento à alta cultura. Portanto, não há sentidos transcendentais e universais, mas apenas sentidos construídos no interior das culturas em contextos históricos específicos. O universal passa a ser visto como a tentativa de imposição de uma visão particular de mundo. Esse entendimento foi central para que Hall (2003) pudesse introduzir na agenda dos estudos culturais uma leitura dos grupos humanos fora dos cânones eurocêntricos, entendendo de outra forma os processos de colonização (não só como processos econômicos, mas também como processos culturais, nos quais houve uma articulação entre classe, raça e gênero, entre outras).

A segunda transformação epistemológica está ligada à linguagem, que Hall (2003) reconhece como o principal meio pelo qual a cultura funciona. Mesmo reconhecendo a influência do pós-estruturalismo e a importância que a linguagem tem na construção e na instituição da realidade, o autor não reduz a realidade à linguagem. Ao argumentar em favor de sua posição, recorre ao exemplo da construção de um muro. Para que seja possível construí-lo, além do conhecimento, dos recursos econômicos, é necessário que haja uma justificativa para a construção desse muro, a qual se constrói pela linguagem. Embora a justificativa seja o produto mais óbvio da linguagem, o conhecimento também está relacionado à linguagem, assim como os recursos econômicos.

Da mesma maneira, quando se fala em justiça econômica, o que entra em cena é a linguagem utilizada para dizer o que se entende por ela. Portanto, em tudo é possível perceber a dimensão da linguagem. Entretanto, é isso "[...] não significa que os processos econômicos tenham sido reduzidos aos discursos e à linguagem. Significa que a dimensão discursiva ou de significado é uma das condições constitutivas do funcionamento da economia" (HALL, 1997, p. 34). Logo, atribuir à linguagem uma posição privilegiada no processo de construção da realidade não significa que realidade e linguagem são a mesma coisa. Contudo, a linguagem passa a ter uma importância muito maior, sendo central, inclusive, naquilo que é considerado natural. Não existe nada fora da linguagem, ou seja, os "[...] fatos naturais, são, portanto, também fenômenos descritivos" (HALL, 1997, p. 29). Se a linguagem faz parte de qualquer realidade, ao ser modificada, modifica-se também a realidade.

Em Freire, desde seus primeiros escritos, como já apontamos, muito focados na questão de classe, a questão cultural não está ausente. Há uma crítica muito forte ao elitismo cultural. Segundo esse elitismo, a classe trabalhadora não possui cultura; “[...] para eles [elitistas], a 'incultura' do povo é tal 'que lhes' parece um absurdo falar da necessidade de respeitar a 'visão do mundo' que ele esteja tendo. Visão do mundo têm apenas os profissionais" (FREIRE, 2011, p. 210). O autor argumenta que isso produz uma educação na qual a ideia de ouvir o povo não faz o menor sentido, pois “[...] para eles [elitistas], 'a ignorância absoluta' do povo não lhe permite outra coisa senão receber os seus ensinamentos” (FREIRE, 2011, p. 210). 
O que é interessante de perceber é que, mesmo na sua obra mais conhecida, Pedagogia do oprimido, Freire (2011) já mostrava a necessidade de transformar a cultura e o entendimento do que significa a cultura, dissociando-a do conhecimento da elite. Para ele, a transformação de realidade requer a transformação da cultura, visto que "[...] a reconstrução da sociedade, que não se pode fazer mecanicistamente, tem, na cultura que culturalmente se refaz, por meio desta revolução, o seu fundamental instrumento" (FREIRE, 2011, p. 214). Portanto, em Freire, desde o início, está presente a importância da cultura. Cultura e economia articulam-se, intensificando a opressão. A postura autoritária e antidialógica leva a "[...] oprimir mais, não só economicamente, mas culturalmente, roubando ao oprimido conquistado sua palavra também, sua expressividade, sua cultura" (FREIRE, 2011, p. 187, grifos nossos).

Observamos que, no momento inicial de sua obra, a concepção de cultura presente tem forte influência do marxismo (cultura dominante x cultura dominada), enfatizando mais o processo de imposição e dominação cultural. Entretanto, ao falar da capacidade que as classes populares têm de fazer a leitura do mundo, de produzir conhecimento, está presente a ideia de que todos os seres humanos são produtores de cultura, e não apenas reprodutores. Essa concepção vai se modificando, com as experiências que o autor teve com diferentes culturas, em diferentes partes do mundo e diferentes movimentos de luta contra a opressão. Nas últimas obras, vê-se Freire aproximando-se do multiculturalismo:

A multiculturalidade não se constitui na justaposição de culturas, muito menos no poder exacerbado e uma sobre as outras, mas liberdade conquistada, no direito assegurado de mover-se cada cultura no respeito uma a outra, correndo risco livremente de ser diferente, sem medo de ser diferente, de ser cada uma 'para si'. (FREIRE, 1999, p. 156, grifos do autor).

Com a aproximação do multiculturalismo, a cultura não representa mais apenas uma relação de domínio articulada com a classe, mas a diferença cultural, juntamente a outras diferenças (de raça, de gênero, linguística), ganha cada vez mais espaço nas teorizações de Freire (1999), destacando, inclusive, a importância de educar para aprender a conviver com a diferença cultural. A multiculturalidade é um projeto histórico "[...] que implica decisão, vontade política, mobilização, organização de cada grupo cultural com vistas a fins comuns. Que demanda, portanto, uma certa prática educativa coerente com esses objetivos. Que demanda uma nova ética fundada no respeito às diferenças" (FREIRE, 1999, p. 157). Com as discussões multiculturais, Freire, que se referia à linguagem como instrumento de dominação cultural e de classe, passa também a enfatizar o papel da linguagem como elemento de transformação da realidade ao apontar que "[...] não é puro idealismo, acrescente-se, não esperar que o mundo mude radicalmente para que se vá mudando a linguagem. Mudar a linguagem faz parte do processo de mudar o mundo" (FREIRE, 1999, p. 68).

Como se pode perceber, assim como Hall, Freire não vai reduzir o mundo à linguagem, tampouco a transformação do mundo à transformação da linguagem. A linguagem torna-se mais um instrumento de luta (e não O Instrumento), mas precisa estar articulada à prática cotidiana por um mundo não classista, não racista, não sexista. A desconstrução de “[...] qualquer discurso autoritário exige ou nos coloca a necessidade de, concomitantemente com o novo discurso, democrático, antidiscriminatório, nos engajarmos em práticas também democráticas" (FREIRE, 1999, p. 68).

\section{Incorporação dos estudos feministas}

Quanto à questão de gênero como categoria de análise, percebemos, também, movimentos que podem ser aproximados nos autores. Para Hall (2003), a “invasão" do feminismo nos estudos culturais representou uma grande transformação nesse campo, sendo apontada como a segunda 
grande virada teórica dos estudos culturais. Esse momento, como o autor observa, foi muito tenso, especialmente porque os homens que trabalhavam com os estudos culturais - nessa época, ele coordenava o Centro de Estudos Culturais de Birmingham - se viam como homens não machistas, que já haviam superado as relações sexistas; por isso, entenderam que estava na hora de abrirem as portas para as intelectuais feministas. Entretanto, as feministas não entraram pela porta, pelo lugar autorizado pelos homens, mas pela janela, colocando na agenda as suas próprias pautas, e não as imaginadas por eles. Nesse sentido, o feminismo "[...] chegou como um ladrão à noite, invadiu; interrompeu, fez um barulho inconveniente, aproveitou o momento, cagou na mesa dos estudos culturais" (HALL, 2003, p. 209).

Ainda segundo o autor, a invasão do feminismo foi fundamental para que percebessem que a leitura que estavam fazendo das relações de gênero, embora mostrasse sensibilidade com a temática, ainda estava marcada pelo patriarcado. Para Hall (2003, p. 428), “[...] a verdade é que, como clássicos 'novos homens', quando o feminismo realmente surgiu com autonomia, fomos pegos de surpresa por aquilo que nós tínhamos tentado - de forma patriarcal - iniciar". O autor reconhece que a chegada das feministas foi muito tensa; afinal, pretendendo ser feminista, ele não podia opor-se às críticas que recebia das feministas e via-se obrigado a concordar com elas. Mesmo sendo "[...] alvejado como 'inimigo', como a figura patriarcal principal” (HALL, 2003, p. 429), como um homem antifeminista, ele afirma que não tinha como lutar contra isso.

Com essa constatação, o autor retoma uma questão central dos estudos culturais: procurar sempre estar do lado dos que, em um determinado momento histórico, estão em uma situação de desvantagem nas relações de poder. Como afirma Hall (2003), se fosse um grupo de direita a tentar calá-lo, lutaria até a morte para combatê-lo, mas não era: era um grupo com o qual concordava na íntegra na sua luta contra o patriarcado, o machismo, o sexismo.

A partir dessa experiência, o autor entendeu que "[...] viver a política é diferente do que ser abstratamente a favor dela" (HALL, 2003, p. 230). O que percebemos, com essa tensão do feminismo, é que o autor, não só nesse momento, mas ao longo de sua vida, buscou sempre aliar a perspectiva teórica com a qual trabalhava com a prática política que defendia, o que, como veremos mais adiante, também torna possível a proximidade com Paulo Freire.

A experiência com as críticas feministas não foi tão tensa ou, pelo menos, não aparece de forma tão tensa na obra de Freire. Diferentemente de Hall (2003), que já se via como defensor das causas feministas e que, ainda assim, foi surpreendido por elas na luta pelo espaço coordenado por ele, em Freire, vemos que as reflexões das feministas foram sendo incorporadas como compromisso político a partir das críticas à linguagem machista presente na sua obra Pedagogia do Oprimido.

Freire (1999), na Pedagogia da Esperança (primeira edição em 1992), reconhece que não reagiu bem às primeiras cartas que recebeu na década de 1970 criticando-o pela linguagem machista. Lembra que nesse período já tinha uma boa experiência em favor da luta dos oprimidos, já tinha a experiência do exílio, mas o machismo que o habitava o impedia de ver na linguagem uma forma de expressá-lo. Foi, então, aprendendo com as feministas que a linguagem machista e as questões de gênero não são problemas menores, como se com eles não se devesse gastar energia, para lutar contra causas supostamente maiores. De acordo com Freire (1999, p. 68), "[...] agora, ao escrever esta Pedagogia da esperança, em que repenso a alma e o corpo da Pedagogia do oprimido, solicitarei das casas editoras que superem a sua linguagem machista. E não se diga que este é um problema menor porque, na verdade, é um problema maior".

Isso não significa que Freire não trazia algumas questões de gênero nas obras anteriores. No livro Professora sim, tia não: cartas a quem ousa ensinar, publicado em 1982, percebemos Freire (1997) 
chamando atenção à necessidade de quem defende as classes populares atentar para a opressão de gênero: "[...] que dizer, por exemplo, de um homem considerado como progressista que, apesar do discurso em favor das classes populares, se comporta como proprietário de sua família? Homem cujo mandonismo asfixia mulher, filhos e filhas?" (FREIRE, 1997, p. 61). Ele também aponta como essas relações de opressão podem dar-se entre as próprias mulheres, assim como ocorrem no interior da mesma classe, o que é tão bem problematizado na Pedagogia do oprimido, ou, ainda, na intersecção entre classes: "Que dizer da mulher que luta na defesa dos interesses de sua categoria mas que, em casa, raramente agradece à cozinheira pelo copo de água que ela lhe traz e que, em conversas com amigas, chama a cozinheira de 'essa gente'?” (FREIRE, 1997, p. 61).

Contudo, nesse caso, é Freire escrevendo sobre as relações de gênero de outros sujeitos, não sobre as dos seus próprios escritos e das suas próprias formas de ação. Nesse sentido, Freire, assim como Hall, foi aprendendo com a convivência com as feministas a reconhecer a sua postura machista, que não percebia em função da sociedade machista ou do processo educativo machista que recebeu. Como ele mesmo escreve, quando recebia a crítica, lembrava-se do seu tempo de menino, quando lhe ensinaram que, quando se diz "meninos", as meninas estão incluídas. Assim como Hall (2003), Freire soube reconhecer a necessidade de mudar, de incorporar na sua teorização outras formas de opressão, aprendendo, sobretudo, com a experiência de sofrimento de oprimidos e oprimidas - entre essas outras opressões, estavam a de gênero, de linguagem e de raça.

\section{Incorporação dos estudos étnico-raciais}

Como já abordamos, a genealogia dos estudos culturais tem uma forte relação com os teóricos marxistas que reviram o lugar da cultura nas sociedades. Em razão disso, apesar de certa abertura, a inclusão da raça como uma categoria central de análise nos estudos culturais não ocorreu sem tensão. Diferentemente de Freire, Hall (2003) foi discriminado por sua identidade racial desde a infância na Jamaica, um país que desenvolveu o modelo racial à semelhança do Brasil, em que as características físicas fazem com que a pessoa seja vista como "mais" negra ou "menos" negra, o que não se vê em outros países, como Estados Unidos e Inglaterra, onde a divisão é rígida, pois qualquer ascendência negra faz a pessoa ser vista como negra, independentemente das características físicas.

Hall, filho de mãe inglesa e pai com ascendência negra, nasceu com traços que o identificavam mais com o pai do que seus irmãos e, por isso, sempre era chamado pejorativamente de coolie $^{2}$, o que o fez pensar que o pastor rezava para virar branco. Segundo Hall (2003, p. 192), "[...] quando eu era criança e era levado à igreja por uma das minhas avós, pensava que o apelo do pastor negro ao Todo Poderoso, 'Senhor, ilumine nossa escuridão', fosse um pedido bem específico por um pouco de assistência divina pessoal".

Filho de classe média alta, desde cedo foi percebendo que seu pai e ele eram discriminados, principalmente quando frequentavam a "alta" sociedade jamaicana, hegemonicamente branca. Como ele explica, isso sempre o incomodou. Sua irmã, proibida de namorar um jovem estudante de medicina negro, adoeceu; sua mãe, ao contrário dele, opunha-se à independência da Jamaica. Por essas razões, ainda jovem, Hall acabou indo para a Inglaterra para estudar. Segundo ele, essa experiência de vida, de sentir-se fora do lugar, de ser discriminado, foi fundamental para entender que não faz sentido supor que tudo pode ser explicado pela classe. Isso o levou a lutar pela presença da categoria de raça como fundamental para os estudos culturais. No entanto, "[...] fazer com que

\footnotetext{
2 "Os coolies na Jamaica são os indianos, descendentes dos trabalhadores trazidos como semiescravos ao país após a Abolição para substituírem os escravos nas plantações. Coolie denota, se é que é possível, um grau abaixo de 'negro' no discurso da raça” (HALL, 2003, p. 190).
} 
os estudos culturais colocassem na sua agenda as questões críticas de raça, a política racial, a resistência ao racismo, questões críticas da política cultural, consistiu numa ferrenha luta teórica" (HALL, 2003, p. 210).

O autor sempre salientou que "[...] raça é uma categoria discursiva e não uma categoria biológica" (HALL, 1997, p. 37), mostrando que a luta se dá no campo cultural. A raça não é uma categoria que indica uma essência ou natureza humana; “[...] a 'naturalização' é, portanto, uma estratégia representacional que visa fixar a 'diferença' e, assim, ancorá-la para sempre. É uma tentativa de deter o inevitável 'deslizar' do significado para assegurar o 'fechamento' discursivo ou ideológico” (HALL, 2016, p. 171).

Ao questionar as noções fixas de identidades, sejam elas raciais, de gênero ou nacionais, o autor enfatiza os processos históricos e culturais que constroem as identidades e mostra o quanto noções essencializadas, fixas, naturalizadas, biológicas de identidade são a base do próprio racismo. Para Hall (2003, p. 345), “[...] no momento em que o significante 'negro' é arrancado de seu encaixe histórico, cultural e político, e é alojado em uma categoria racial biologicamente constituída, valorizamos, pela inversão, a própria base do racismo que estamos tentando desconstruir".

Ao colocar a raça como categoria de análise, o autor não desqualifica nem diminui a relevância de outras categorias, como as já destacadas categorias de classe e de gênero, o que seria, segundo ele, substituir um determinismo (de classe) por outro determinismo (de raça ou gênero). Para Hall (2003), trata-se de analisar como elas se articulam, se desarticulam e se rearticulam em contextos históricos e culturais específicos, não sendo possível estabelecer a priori o grau de importância de cada uma.

Freire, embora não tenha vivenciado a experiência de ser discriminado por raça, foi reconhecendo a importância dessa categoria em seus estudos. Mesmo nas suas primeiras obras, ainda que focadas na opressão econômica, não deixou de apontar o processo histórico brasileiro de colonização e a escravidão indígena e negra, relacionando-os às teorias racistas da imposição e invasão cultural, que veem os nativos e os negros como sujeitos inferiores:

\begin{abstract}
A invasão cultural, que serve à conquista e à manutenção da opressão, implica sempre na visão focal da realidade, na percepção desta como estática, na superposição de uma visão do mundo na outra. $\mathrm{Na}$ "superioridade" do invasor. $\mathrm{Na}$ "inferioridade" do invadido. $\mathrm{Na}$ imposição de critérios. Na posse do invadido. No medo de perdê-lo. A invasão cultural implica ainda, por tudo isto, em que o ponto de decisão da ação dos invadidos está fora deles e nos dominadores invasores. E, enquanto a decisão não está em quem deve decidir, mas fora dele, este apenas tem a ilusão de que decide. Esta é a razão por que não pode haver desenvolvimento socioeconômico em nenhuma sociedade dual, reflexa, invadida. (FREIRE, 2011, p. 217).
\end{abstract}

Tal problemática mantém-se e adquire maior importância em suas obras na década de 1990. Freire (1999) mostra como, no processo de colonização, “[...] os colonizados são bárbaros, incultos, 'a-históricos', até a chegada dos colonizadores que lhes 'trazem' a história. Falam dialetos fadados a jamais expressar a "verdade da ciência"' (FREIRE, 1999, p. 143). O autor aponta o quanto a experiência colonial marca nossa experiência histórica e o quanto nossa sociedade ainda é colonial. Mesmo após 1822, a sociedade guarda as marcas do período colonial, "[...] portanto, vem se fazendo, historicamente, com valores, comportamentos, normas, hierarquias e preconceitos pautados pela discriminação, pelo autoritarismo e pelo elitismo" (FREIRE, 1999, p. 232).

Nesse sentido, pode-se ver a proximidade entre Hall e Freire pela forma como apontam raça como uma categoria central (não a única), o que, no caso de Freire, fica mais marcante nas suas últimas obras, demonstrando que seu pensamento foi sendo construído em comunhão com a experiência dos oprimidos, devido a questões não exclusivamente de classe, mas também de gênero

Práxis Educativa, Ponta Grossa, v. 16, e2116539, p. 1-16, 2021 Disponível em: <https://www.revistas2.uepg.br/index.php/praxiseducativa> 
e raça. Para Freire (1999, p. 156), “[...] a discriminação racial não pode, de forma alguma, ser reduzida a um problema de classe como o sexismo [...]. Sem, contudo, o corte de classe, eu, pelo menos, não entendo o fenômeno da discriminação racial nem o da sexual". Essa articulação não diminui a importância da raça, mas fortalece a luta para que seus efeitos - em especial, a desigualdade econômica - sejam combatidos.

Assim como Hall, Freire observa que a importância assumida por uma categoria de análise depende de cada contexto, não podendo ser definida teoricamente, mas, sim, na prática. Segundo Freire (2001, p. 46), "[...] por mais que, nesta ou naquela sociedade, por motivos históricos, sociais, culturais, econômicos, seja visivelmente sublinhada a importância da raça, da classe, do sexo, [...] é preciso que evitemos cair na tentação de reduzir a luta inteira a um desses aspectos fundamentais".

\section{Observações finais}

Ainda que se possa falar em convergências teóricas e políticas entre Paulo Freire e Stuart Hall, optamos por não as separar, por entendermos que nenhum deles fazia essa separação. Para eles, toda teoria é necessariamente política, atravessada pela concepção de mundo, de humanidade, de raça, classe e gênero, ainda que nenhuma se reduza a elas.

Trata-se de autores preocupados em questionar os processos de opressão. Suas experiências de vida, marcadas pela convivência com os movimentos sociais, produziu uma teoria/política preocupada em transformar a realidade, sobretudo daqueles que vivem intensamente processos de opressão e que trazem marcas de contextos coloniais, de classe, raça e gênero.

Ambos os autores articularam os processos de transformação não baseada apenas na luta de classe, mas na luta cultural. Stuart Hall "[...] talvez pareça um estranho no ninho da teoria contemporânea porque seu utopismo é descendente da cultura" (SOVIK, 2014, p. 78). De modo semelhante, vemos Paulo Freire, que desde o início foi um crítico da dominação cultural de classe, perceber no processo de transformação da cultura e da linguagem uma parte da luta pela transformação do mundo.

O desenvolvimento da crítica ao determinismo econômico que ambos fizeram sempre esteve ligado ao engajamento político que oportunizou várias aprendizagens com os movimentos sociais, fossem estes de classe, gênero ou raça. Com isso, foram construindo um modelo teórico/político no qual não há espaço para reducionismos, mas articulações, possibilidades, contingências, tensões ou até mesmo, como diria Hall (2003), irritações e ruídos retumbantes, ou, como diria Freire (2002), a justa ira e a indignação.

Trata-se de autores que foram capazes de questionar a teoria crítica de sua época, não para combatê-la, mas para desenvolvê-la e ampliá-la. Mostraram que certa compreensão do marxismo levava a um determinismo econômico que, mesmo não tendo a intenção, produzia o fatalismo ou um ativismo ingênuo. Ao questionarem certo tipo de marxismo, sem abandonarem Marx, produziram uma teoria/política capaz de responder aos tempos que estavam emergindo, tempos de políticas identitárias, mas sem abrir mão de transformar as relações sociais e identificar alternativas. Tampouco renunciaram à necessária defesa da redistribuição econômica, o que os fez manter a categoria de classe como categoria de análise fundamental - não única, mas uma das centrais, junto à cultura, à raça/etnia, ao gênero e a outras, conforme as especificidades históricas. Inspirando-nos em Santos (2019, p, 352), podemos dizer que ambos sabiam que "[...] a ausência de alternativas só é intelectualmente convincente para quem não precisa delas existencialmente na sua vida diária". 
Como diz Hall (2003, p. 370), você não pode fazer da crítica "[...] um parque de diversões intelectual", no sentido de supor que o importante é mostrar que tem inteligência suficiente para desmontar uma teoria. É preciso propor algo, ainda que esse algo não dure pare sempre. Ou, como dizia Freire (1997, p. 47), a "[...] dor imposta às classes populares brasileiras [...] nos empurra, nos estimula à luta política pela mudança radical do mundo". Com ambos, aprendemos que estamos em um "[...] campo de batalha permanente, onde não se obtêm vitórias definitivas, mas onde há sempre posições estratégicas a serem conquistadas ou perdidas” (HALL, 2003, p. 255).

Para finalizar, entendemos que, com tantas possibilidades de convergência, temos razões suficientes para articular o pensamento de Paulo Freire com os estudos culturais. Talvez a convergência entre os autores seja um caminho promissor para forjarmos os "inéditos viáveis" pelo qual Freire lutava desde a Pedagogia do Oprimido.

\section{Referências}

APPLE, M. W. Ideologia e currículo. Porto Alegre: Artes Médicas, 2006.

BAUMAN, Z. Modernidade líquida. Rio de Janeiro: Jorge Zahar, 2001.

COSTA, M. V.; WORTMANN, M. L. C.; SILVEIRA, R. M. H. Stuart Hall: tributo a um autor que revolucionou as discussões em educação no Brasil. Educação \& Realidade, Porto Alegre, v. 39, n. 2, p. 635-649, abr./jun. 2014. DOI: https://doi.org/10.1590/s2175-62362014000200015

ESCOSTEGUY, A. C. D. Uma introdução aos Estudos Culturais. Revista FAMECOS, Porto Alegre, n. 9, p. 87-97, dez. 1998. DOI: https://doi.org/10.15448/1980-3729.1998.9.3014

FREIRE, P. Professora sim, tia não: cartas a quem ousa ensinar. 8. ed. São Paulo: Olho d'água, 1997.

FREIRE, P. Pedagogia da autonomia: saberes necessários à prática educativa. 24. ed. São Paulo: Paz e Terra, 2002.

FREIRE, P. Pedagogia da tolerância. São Paulo: UNESP, 2004.

FREIRE, P. Pedagogia da esperança: um reencontro com a pedagogia do oprimido. 6. ed. São Paulo: Paz e Terra, 1999.

FREIRE, P. Pedagogia do oprimido. 50. ed. São Paulo: Paz e Terra, 2011.

FREIRE, P. Política e educação. 5. ed. São Paulo: Cortez, 2001.

GIROUX, H. A. Os professores como intelectuais: rumo a uma pedagogia crítica da aprendizagem. Porto Alegre: Artes Médicas, 1997.

HALL, S. A centralidade da cultura: Notas sobre as revoluções culturais do nosso tempo. Educação \& Realidade, Porto Alegre, v. 22, n. 2, p. 15-46, jul./dez. 1997.

HALL, S. Cultura e representação. Rio de Janeiro: Ed. PUC-Rio: Apicuri, 2016.

HALL, S. Da diáspora: identidades e mediações culturais. Belo Horizonte: UFMG, 2003. 
HOOKS, B. Mulheres negras: moldando a teoria feminista. Revista Brasileira de Ciência Política, Brasília, n. 16, p. 193-110, jan./abr. 2015. DOI: http://dx.doi.org/10.1590/0103$\underline{335220151608}$

LIMA, L. C. Três razões para estudar Freire hoje, para além da mais óbvia. In: GADOTTI, M.; CARNOY, M. (org.). Reinventando Freire: a práxis do Instituto Paulo Freire. São Paulo: Instituto Paulo Freire e Lemann Center; Stanford Graduate School of Education, 2018. p. 29-36.

MCLAREN, P. A vida nas escolas: uma introdução à pedagogia crítica nos fundamentos da educação. Porto Alegre: Artes Médicas, 1997.

PAULA, L. C. de; PORTELLA, B. M. Entrevista com Peter McLaren: Discussões radicais e esperançosas sobre tempos de brutal conservadorismo - caminhos de luta e transformação à luz de Paulo Freire. Práxis Educativa, Ponta Grossa, v. 16, e2117204, p. 1-22, 2021. DOI: https://doi.org/10.5212/praxeduc.v.16.17204.010

SANTOS, B. S. O fim do império cognitivo: a afirmação das epistemologias do Sul. Belo Horizonte: Autêntica Editora, 2019.

SOVIK, L. Stuart Hall - Notas dissonantes. Revista de Epistemologias da Comunicação, São Leopoldo, v. 2, n. 4, p. 72-79, jul./dez. 2014.

WORTMANN, M. L. C.; COSTA, M. V.; SILVEIRA, R. M. H. Sobre a emergência e a expansão dos Estudos Culturais em educação no Brasil. Educação, Porto Alegre, v. 38, n. 1, p. 32-48, jan./abr. 2015. DOI: https://doi.org/10.15448/1981-2582.2015.1.18441

WORTMANN, M. L. C.; SANTOS, L. H. S.; RIPOLL, D. R. Apontamentos sobre os Estudos Culturais no Brasil. Educação \& Realidade, Porto Alegre, v. 44, n. 4, p. 1-22, 2019. DOI: https://doi.org/10.1590/2175-623689212

Recebido em 01/08/2020

Versão corrigida recebida em 13/02/2021

Aceito em 14/02/2021

Publicado online em 18/02/2021

Práxis Educativa, Ponta Grossa, v. 16, e2116539, p. 1-16, 2021

Disponível em: <https://www.revistas2.uepg.br/index.php/praxiseducativa> 